\title{
www.czasopisma.pan.pl \\ The Impact of Microwave Penetration Depth on the Process of Heating the Moulding Sand with Sodium Silicate
}

\author{
D. Nowak \\ Department of Foundry Engineering, Plastics and Automation, Wrocław University of Science and Technology, \\ ul. Smoluchowskiego 25, 50-372 Wrocław, Poland \\ Corresponding author. E-mail address: daniel.nowak@pwr.edu.pl
}

Received 27.06.2017; accepted in revised form 05.09.2017

\begin{abstract}
This paper presents the impact of microwave penetration depth on the process of heating the moulding sand with sodium silicate. For each material it is affected by: the wavelength in vacuum and the real and imaginary components of the relative complex electrical permittivity $\varepsilon_{r}$ for a selected measurement frequency. Since the components are not constant values and they change depending on the electrical parameters of materials and the frequency of the electromagnetic wave, it is indispensable to carry out laboratory measurements to determine them. Moreover, the electrical parameters of materials are also affected by: temperature, packing degree, humidity and conductivity. The measurements of the dielectric properties of moulding sand with sodium silicate was carried out using the perturbation method on a stand of waveguide resonance cavity. The real and imaginary components of the relative complex electrical permittivity was determined for moulding sand at various contents of sodium silicate and at various packing degrees of the samples. On the basis of the results the microwave penetration depth of moulding sand with sodium silicate was established. Relative literature contains no such data that would be essential to predicting an effective process of microwave heating of moulding sand with sodium silicate. Both the packing degree and the amount of sodium silicate in moulding sand turned out to affect the penetration depth, which directly translates into microwave power density distribution in the process of microwave heating of moulding sand with sodium silicate.
\end{abstract}

Keywords: Innovative foundry materials and technologies, Penetration depth, Microwaves, Electrical permittivity, Moulding sand

\section{Introduction}

The microwave technology is applied in various fields of science, technology, industry and medicine. Its use is also investigated in the foundry industry with an aim of finding an effective way of drying and curing moulding and core materials by applying microwave radiation. The microwave heating is related to the polarisation effect in dielectric and semiconductor charge material to which the electromagnetic energy of great frequency is supplied by means of waveguides. As a result of the polarisation, the electromagnetic waves are refracted, reflected and attenuated in dielectrics. It becomes essential then for the electromagnetic field to penetrate and be absorbed in an effective microwave heating by the charge material at a greatest depth, which consequently affects the active power in the charge material. The application of the microwave heating became attractive for the industry due to a number of characteristic features, including the possibility to obtain high power density and the highly selective heating method, which results in heating the charge material, not the environment, a short heating time, a 
low thermal inertia as well as the possibility of easy automation [1].

The moulding sand commonly used in foundry processes is a mixture of various materials processed in a specific way and selected in terms of quality and quantity. The main component of the moulding sand are various kinds of sands of a low conductivity (therefore regarded as dielectric). The most important electrical parameters include cross and surface resistivity, electrical permittivity and dielectric loss factor, dielectric strength, partial discharge resistivity as well as electrisation susceptibility [2]. However, it is the electrical permittivity $(\varepsilon)$ that is one of more essential electrical parameters participating in the moulding and core sand microwave heating. This parameter specifies the electrical properties of the environment as it describes the macroscopic properties of the dielectric in the electric field at various frequencies. In a number of research centres of world renown it became the research focus of investigations into sands and clays used as grains in the moulding or core sand [3-7] and into sand-based mixtures [8-13].

\section{Microwave heating}

During the microwave heating the electromagnetic wave attenuation can be observed inside the charge material, following the application of large frequencies. If a plane electromagnetic wave of a particular surface power density hits the dielectric $\left(P_{i n}\right)$, a part of its density is reflected $\left(P_{\text {out }}\right)$, while another part is absorbed by the dielectric $\left(P_{a b s}\right)$.

$P_{a b s}=P_{\text {in }}-P_{\text {out }}$

Figure 1 demonstrates the distribution of power density absorbed by the dielectric at a plane wave.

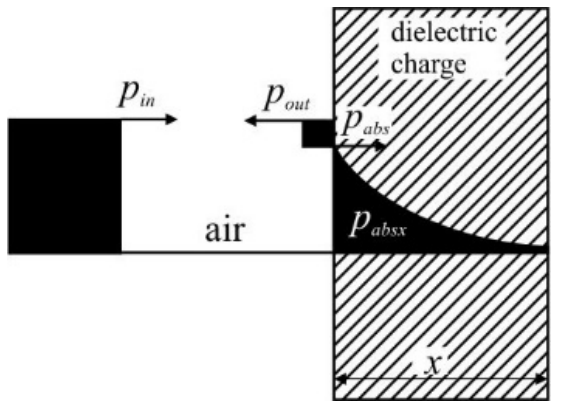

Fig.1. Distribution of power density absorbed by the dielectric at a plane wave

If $E_{0}$ means the value of electrical field intensity on the surface of the charge material, then its distribution is specified as a function of a distance $x$ from the surface:

$E_{x}=E_{0} e^{-\frac{x}{D_{p}}}$

where:
$E_{x}$ - intensity dependent on depth $x\left[V \cdot \mathrm{m}^{-1}\right]$,

$E_{0}$ - intensity on the boundary surface $\left[\mathrm{V} \cdot \mathrm{m}^{-1}\right]$,

$D_{p}$ - penetration depth [m].

One of the components of the field intensity inside the dielectric is the penetration depth specified as a distance at which the field intensity $E_{x}$ decreases $e$ times in comparison to the surface. It is one of the most important parameters of the microwave heating $[14,15]$ described by the following equation [16]:

$D_{p}=\frac{\lambda_{0}}{2 \pi\left(2 \varepsilon^{\prime}\right)^{1 / 2}}\left\{\left[1+\left(\frac{\varepsilon^{\prime \prime}}{\varepsilon^{\prime}}\right)^{2}\right]^{1 / 2}-1\right\}^{-1 / 2}$

where:

$\lambda_{0}$ - wavelength in vacuum for a given frequency [m], $\varepsilon^{\prime}$ - real component of the relative complex electrical permittivity, $\varepsilon^{\prime \prime}$ - imaginary component of the relative complex electrical permittivity.

As equation (3) demonstrates the following data are required in order to calculate the microwave penetration depth to the inside of the charge material: wavelength in vacuum for a given frequency ( $\lambda_{0}$ for the frequency of $2.45 \mathrm{GHz}$ equals $0.122[\mathrm{~m}]$ ), the value of the real and imaginary component of the relative complex electrical permittivity $\varepsilon_{r}$.

The relative complex electrical permittivity $\varepsilon_{r}$ is defined by the relation:

$\varepsilon_{r}=\varepsilon^{\prime}-j \varepsilon^{\prime \prime}$

The real component of the relative complex electrical permittivity represents the ability of a material to store energy, whereas the imaginary component represents the ability of a dielectric to disperse the energy stored in the electrical field, i.e. to generate losses.

It should be mentioned that a relative dielectric permittivity is not constant as it changes depending on the electrical parameters and the frequency of the electromagnetic wave. Furthermore, it is affected by temperature, packing degree, humidity, and the conductivity of materials [1]. In the case of moulding sand with sodium silicate the electrical permittivity is also considerably affected by the packing degree of moulding sand [13]. The relative electrical permittivity of liquids and solids ranges from 1 to 100 . Table 1 shows an exemplary value of relative electrical permittivity and field penetration depth at a frequency of $3 \mathrm{GHz}$ for selected dielectrics.

The volume power density $p_{a b s x}$ in the charge material at a distance $x$ from the surface can be described by the relation:

$p_{a b s x}=p_{a b s 0} \cdot e^{-2 x / D_{p}}$

where:

$p_{a b s 0}$ - power per volume unit at the surface.

Data on the power density distribution for a given charge material enables the determination of the heating effect, i.e. an increase in the charge material temperature.

Since no data can be found in relevant literature on the microwave penetration depth for moulding sand with sodium silicate, the main purpose of this study was to determine the 
electrical properties of the sands and based on equation (3) determine the microwave penetration depth during the heating process. The electrical properties of moulding sand were established as a function of their packing degree and the amount of sodium silicate. The main component of moulding sands was medium-grain silica sand with the grain fineness of 0.20/0.315/0.16 (Company - Grudzeń Las) and sodium silicate type 137, 145 and 150 with 2,4 and $6 \%$ parts by weight (Chemical Plant Rudniki S.A.). The measurements of electrical properties of concentrated samples were carried out using the perturbation method on a stand of waveguide resonance cavity in accordance with the measurement methodology specified in [17].

Table 1.

Relative electrical permittivity of selected materials and the field penetration depth at a frequency of $3 \mathrm{GHz}$ [1]

\begin{tabular}{llccc}
\hline No & Material & $\mathbf{T}\left[{ }^{\mathbf{0}} \mathbf{C}\right]$ & $\boldsymbol{\varepsilon}_{\boldsymbol{r}}$ & $\boldsymbol{D}_{\boldsymbol{p}}[\mathbf{m}]$ \\
\hline 1. & Water & 25 & 76.7 & 0.023 \\
\hline 2. & Ice & -12 & 3.20 & 19.77 \\
\hline 3. & Polystyrene & 25 & 2.55 & 60.42 \\
\hline 4. & Teflon & 22 & 2.10 & 146.44 \\
\hline 5. & Table salt & 25 & 2.26 & 32.76 \\
\hline 6. & Aluminium oxide & 25 & 8.79 & 3.62 \\
\hline 7. & Fused quartz & 25 & 3.78 & 246.91 \\
\hline
\end{tabular}

\section{Results}

The microwave penetration depth for moulding sand with sodium silicate determined by the measurements of the relative electrical permittivity and dependent on the sand packing degree and the amount of sodium silicate is presented in Figures 2 to 4 . A square type of surface matching of charts has been used.

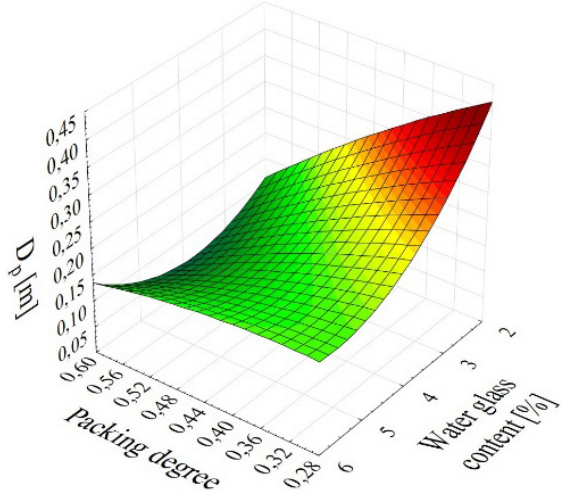

Fig. 2. The impact of packing degree and amount of sodium silicate on the microwave penetration depth in moulding sand with sodium silicate 137

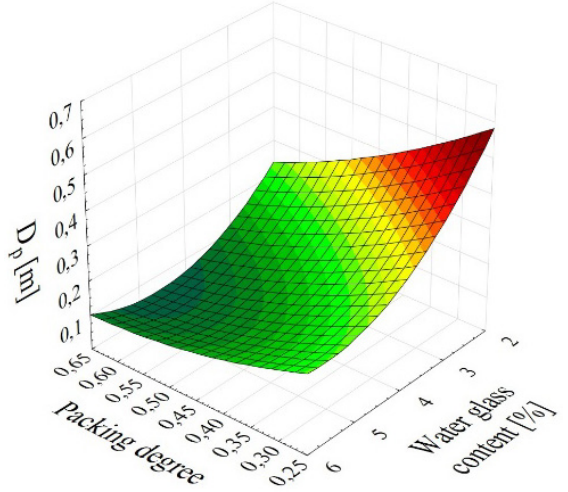

Fig. 3. The impact of density and amount of sodium silicate on the microwave penetration depth in moulding sand with sodium silicate 145

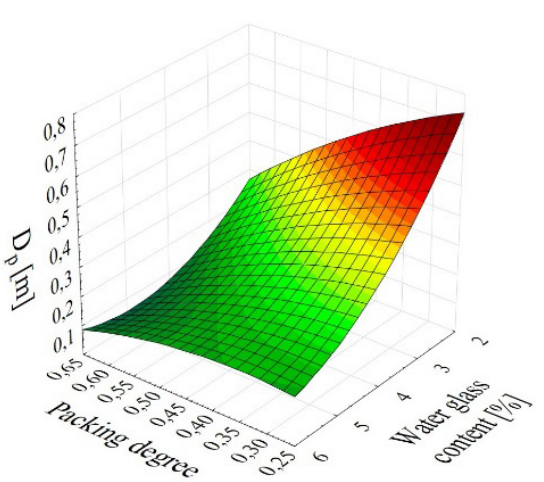

Fig. 4. The impact of packing degree and amount of sodium silicate on the microwave penetration depth in moulding sand with sodium silicate 150

The results presented in Figures 2 to 4 demonstrate that along with an increase in the packing degree the microwave penetration depth in moulding sand decreases linearly e.g. from the value of $D_{p}=0.38[\mathrm{~m}]$ to $D_{p}=0.16[\mathrm{~m}]$ for the moulding sand with $2 \%$ sodium silicate 137 , and from $D_{p}=0.50[\mathrm{~m}]$ to $D_{p}=0.31[\mathrm{~m}]$ for the moulding sand with $2 \%$ sodium silicate 145 . The same change can be observed for the moulding sand with $2 \%$ sodium silicate 150 . In the latter case, the penetration depth changes respectively from $D_{p}=0.76[\mathrm{~m}]$ to $D_{p}=0.38[\mathrm{~m}]$.

The penetration depth also decreases linearly for all types of sodium silicate if the amount of sodium silicate in moulding sand changes. For example, from minimum $D_{p}=0.38[\mathrm{~m}]$ to maximum $D_{p}=0.76[\mathrm{~m}]$ for the moulding sand with $2 \%$ sodium silicate 150 . The changes result from the fact that along with an increase in the packing degree of moulding sand and the amount and type of sodium silicate the imaginary component of the relative complex electrical permittivity $\left(\varepsilon^{\prime \prime}\right)$ undergoes changes, which in turn results in diispersing the energy stored in the electric field and affects the extent of losses in the charge material. 


\section{Conclusions}

During the microwave heating of the moulding sand with sodium silicate the microwave penetration depth considerably affects the efficiency and effectiveness of this process.

An increase in the amount of sodium silicate and the packing degree of the moulding sand results in decreasing the microwave penetration depth into the moulding sand. The penetration depth is also affected by the type of grain used: along with a change in its packing degree the microwave penetration depth increases.

As a result of the field attenuation and concentration of heating sources at the surface the microwave heating is less efficient.

The results on the microwave penetration depth into the moulding sand with sodium silicate may be applied for the purposes of selecting the moulding sand composition and heating parameters as well as designing microwave heating devices.

Further research on the impact of microwave penetration depth into the moulding sand with sodium silicate on the process of microwave heating will be carried out with regard to temperature, type of sodium silicate and type of grain.

\section{Acknowledgement}

The research was financially supported from the grant for statutory activity No. 0401/0031/17.

\section{References}

[1] Hering, M. (1998). Electrothermal basics part 2. Warszawa: WNT. (in Polish).

[2] Lisowski, M. (2004). Measurement of resistivity and permeability of electrical dielectric constant. Wrocław: Oficyna Wydawnicza Politechniki Wrocławskiej. (in Polish).

[3] Chenhui, L., Libo, Z., Jinhui, P., Srinivasakannan, Ch., Liu, B., Hongying, X., Junwen, Z. \& Lei, X. (2013). Temperature and moisture dependence of the dielectric properties of silica sand. The Journal of Microwave Power and Eelectromagnetic Energy. 47(3), 199-209.

[4] Fratticcioli, E., Dionigi, M. \& Sorrentino, R. (2003). A New Permittivity Model for the Microwave Moisture Measurement of Wet Sand. 33rd European Microwave Conference, 2-10 Oct. 2003 (pp.539-542) Munich, Germany. DOI: 10.1109/EUMA.2003.341009.

[5] Abidin, K. (2001). Electrical Spectroscopy of Kaolin and Bentonite Slurries. Turk J Engin Environ Sci. 25, 345-354.
[6] Hashemi, A., Rashidi, M., Kurtis, K.E., Donnell, K.M. \& Zoughi, R. (2016). Microwave dielectric properties measurements of sodium and potassium water glasses. Materials Letters. 69, 10-12.

[7] Grabowska, B. (2009). Microwave crosslinking of polyacrylic compositions containing dextrin and their applications as molding sands binders. Polymers, 54(7-8), 507-513.

[8] Abidin, K. \& Hsai-Yang F. (1997). Identification of contaminated soils by dielectric constant and electrical conductivity. Journal of Environmental Engineering. 123(2), 169(9). DOI 10.1061/(ASCE)0733-9372(1997)123:2(169.

[9] Tong, L., Haihui, Z. \& Xingfa, G. (2014). The complex permittivity measurement of powder materials and the dielectric constant of lunar soil. Measurement. 48, 6-12.

[10] Shi, W., Qi, Z., Gang, W., Lei, Y., \& Cheng, L. (2011). The relationship between electrical capacitance-based dielectric constant and soil water content, Environmental Earth Sciences. 62(5), 999-1011.

[11] Huafang, W., Wenbang, G. \& Jijun, L. (2014). Improve the Humidity Resistance of Sodium Silicate Sands By EsterMicrowave Composite Hardening. Metalurgija, 53(4), 455458.

[12] Grabowska, B., Sitarz, M., Olejnik, E., Kaczmarska, K. \& Tyliszczak, B. (2015). FT-IR and FT-Raman studies of cross-linking processes with $\mathrm{Ca} 2+$ ions, glutaraldehyde and microwave radiation for polymer composition of poly(acrylic acid)/sodium salt of carboxymethyl starch - In moulding sands, Part II. Spectrochim. Acta Part A Mol. Biomol. Spectrosc. 151, 27-33. DOI: 10.1016/j.saa.2015.06.084.

[13] Stachowicz, M., Opyd, B. \& Granat, K. (2015). Comprehensive assessment of polymeric materials for foundry tooling used in microwave field. Arch. Metall. Mater. 60(1), 335-339. DOI: 10.1515/amm-2015-0055.

[14] Linxin, Y., Weiqiang, Q., Yalan, Y., Kyung Ho, R., Yudong, Ch. \& Yinzhe, J. (2017). Dielectric properties of Antarctic krill (Euphausia superba) and white shrimp (Penaeus vannamei) during microwave thawing and heating. Journal of Microwave Power and Electromagnetic Energy. 51, 3-30. DOI: 10.1080/08327823.2017.1291067.

[15] Mujumdar, A.S. (2014). Handbook of Industrial Drying. $\left(4^{\text {th }}\right.$ ed.). CRC Press.

[16] Peng, Z., Hwang, J., Mouris, J., Hutcheon, R. \& Huang, X. (2010). Microwave Penetration Depth in Materials with Nonzero Magnetic Susceptibility. ISIJ International. 50 (11), 1590-1596.

[17] Opyd, B., Granat, K. \& Nowak, D. (2015). Determination of electrical properties of materials used in microwave heating of foundry moulds and cores. Metalurgij., 54 (2), 347-349. 